\title{
ГЕОИНФОРМАЦИОННАЯ СИСТЕМА ДЛЯ АНАЛИЗА ДАННЫХ ЭКОЛОГИЧЕСКОГО МОНИТОРИНГА УКРАИНСКОЙ ЧАСТИ ДЕЛЬТЫ ДУНАЯ
}

\author{
К. б. н. Васенко А. Г., \\ к. т. н. Брук В. В., \\ аспирант Свиридов Ю. В.
}

Украина, г. Харьков, Украинский научно-исследовательский институт экологических проблем

DOI: https://doi.org/10.31435/rsglobal_sr/31052019/6489

\section{ARTICLE INFO}

Received 29 March 2019

Accepted 17 May 2019

Published 31 May 2019

\section{KEYWORDS}

geographic information system, ecological monitoring, water quality parameters, temporal trend, significance, Holt method, maximum available concentration.

\begin{abstract}
For forecasting of the change of water quality in Ukrainian part of Danube delta the geographic information system (GIS) of the ecological monitoring had been designed. To this GIS a number of functions had been added including the function of the analysis of the temporary rows of observation results. By means of designed GIS the main trends of the change of the water quality for period, since 2004, have been identified. For majority of the water quality parameters the trends to improvement of water quality have been identified. The trend to deterioration of water quality has been identified for manganese concentration only. Increasing of manganese concentrations existed already in the inlet checkpoint of Ukrainian part of Danube delta (above Reni).
\end{abstract}

Citation: Васенко А. Г., Брук В. В., Свиридов Ю. В. (2019) Geoinformacionnaya Sistema dlya Analiza Dannyh Ekologicheskogo Monitoringa Ukrainskoj Chasti Del'ty Dunaya. Science Review. 4(21). doi: 10.31435/rsglobal_sr/31052019/6489

Copyright: (C) 2019 Васенко А. Г., Брук В. В., Свиридов Ю. В. This is an open-access article distributed under the terms of the Creative Commons Attribution License (CC BY). The use, distribution or reproduction in other forums is permitted, provided the original author(s) or licensor are credited and that the original publication in this journal is cited, in accordance with accepted academic practice. No use, distribution or reproduction is permitted which does not comply with these terms.

Введение. Понизовье Дуная и его дельта в пределах Украины относится к категории трансграничных объектов. Поэтому экологическое состояние дельты Дуная представляет интерес, как на национальном, так и на международном уровне. В первую очередь, это связано с выполнением плана действий Международной Комиссии по защите реки Дунай (International Commission for the Protection of the Danube River - ICPDR) [1]. Для разработки мероприятий по уменьшению влияния антропогенных факторов нужна объективная оценка экологического состояния дельты р. Дунай, в особенности, оценка качества воды в различных рукавах речной дельты.

В целях наглядного отображения пространственно-временной динамики качества воды дельты р. Дунай для анализа результатов экологического мониторинга целесообразно применение геоинформационных технологий. Однако, в разработанной в рамках проекта ICPDR ГИС [2] отсутствуют функции выявления тенденций и прогнозирования изменения показателей качества воды. В существующей в Украине ГИС мониторинга качества поверхностных вод Госводагентства Украины [3], а также в региональных ГИС некоторых суббассейнов рек [4-6] также отсутствуют аналогичные функции. Поэтому в целях объективной оценки качества воды дельты р. Дунай и выявления тенденций его изменения была разработана геоинформационная система (ГИС) украинской части дельты р. Дунай, включающая аналитическую подсистему с функциями комплексной оценки качества речной воды и прогнозирования его изменения. 
Методика исследований. Разработанная ГИС представляет собой интерактивную электронную карту украинской части дельты Дуная, связанную с базою данных, содержащей информацию о результатах мониторинга качества воды за период 2005-2017 гг., осуществляемого Дунайской гидрометеообсерваторией (ГМО) и Украинским научноисследовательским институтом экологических проблем (УКРНИИЭП) [7-8]. Схема расположения пунктов мониторинга приведен на рис. 1. Структура аналитического блока ГИС с функциями прогнозирования изменения качества воды приведена на рис. 2.

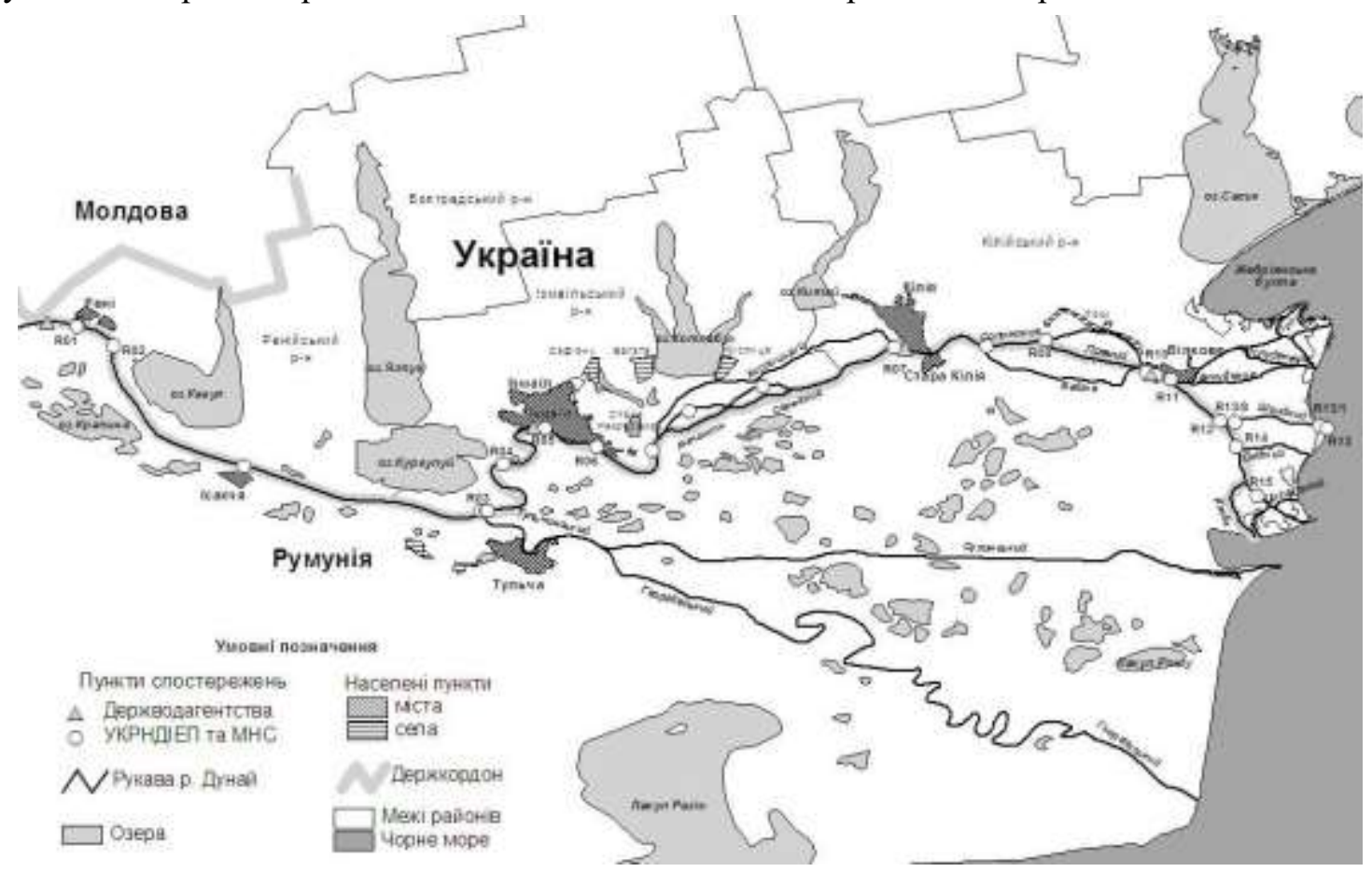

Рис. 1. Схема расположения пунктов мониторинга качества воды в украинской части дельты

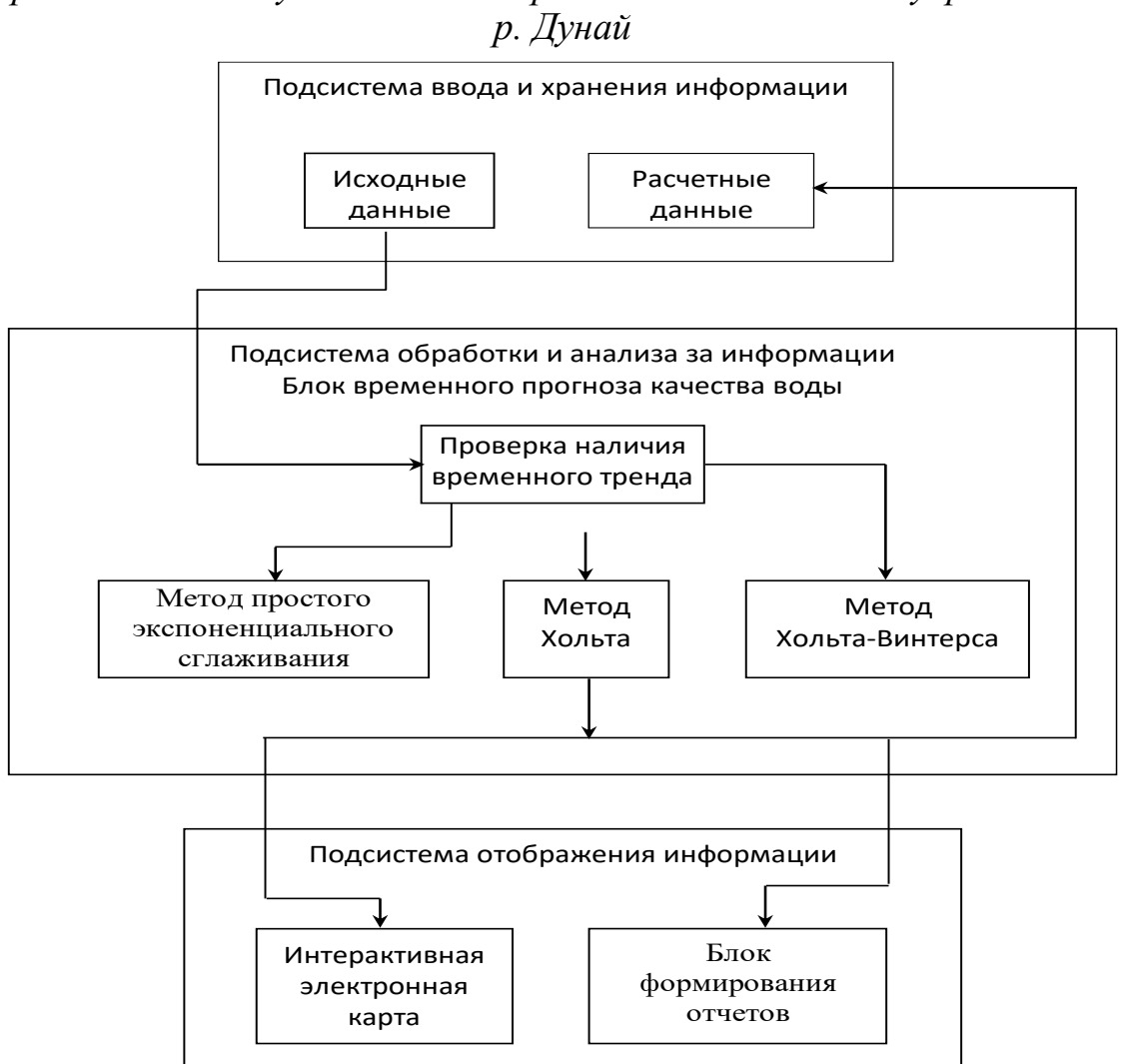

Рис. 2. Общзая схема алгоритма прогнозирования значений показателей качества речных вод на определенный период времени 
Выбор конкретного метода прогнозирования зависит от наличия или отсутствия временной тенденции для прогнозируемого показателя. Если значимая тенденция временного изменения показателя не выявлена, для прогнозирования используется метод простого экспоненциального сглаживания. В противном случае для прогнозирования используется метод Хольта или метод Хольта-Винтерса. Метод Хольта применяется для прогнозирования среднегодовых значений показателей; метод Хольта-Винтерса - для прогнозирования среднемесячных или среднеквартальных значений (учета сезонных индексов).

На первом этапе прогнозирования рассчитывалась временная тенденция показателя и определялась ее значимость. Временная тенденция изменения показателя (a1) рассчитывалась как коэффициент линейной регрессии при независимой переменной в уравнении

$$
C=a_{0}+a_{1} \cdot t
$$

где $C$ - показатель, прогнозируется, $t$ - время, $a_{0}$ - свободный член уравнения регрессии.

Значения коэффициентов регрессии, в том числе и временной тенденции, рассчитывались методом наименьших квадратов.

Для определения значимости временной тенденции показателя рассчитывалась следующая статистика:

$$
f=\frac{a_{1}}{\sigma_{1}},
$$

где $\sigma_{1}$ - погрешность выборочной оценки коэффициента $a_{1}$, определяемая по формуле

$$
\sigma_{1}=\frac{\sigma_{u}}{S_{t}},
$$

$\sigma_{u}-$ стандартная погрешность регрессии,

$S_{t}$ - среднеквадратическое отклонение переменной $t$.

Значение статистики $f$, рассчитанные по формулам (2)-(4), сопоставлялись с критическим значением распределения Стюдента $f_{\alpha}$ при заданном уровне значимости $\alpha$ для одностороннего критерия.

В данной работе краткосрочное прогнозирование качества воды в пунктах наблюдений осуществлялось только по показаниям, для которых была обнаружена временная тенденция на уровне значимости не больше 5\% (доверительная вероятность не менее 95\%). Для анализа временных изменений качества воды были использованы данные по 11-ти пунктам мониторинга, где наблюдения осуществлялись регулярно (табл. 1).

\begin{tabular}{|c|c|c|}
\hline $\begin{array}{c}\text { Код пункта } \\
\text { мониторинга }\end{array}$ & Местоположение пункта мониторинга & $\begin{array}{c}\text { Расстояние от } \\
\text { устья } \\
\end{array}$ \\
\hline R01 & Дунай - выше Рени & 71 миля \\
\hline R02 & Дунай - ниже Рениі & 68 миля \\
\hline R03 & Дунай - ниже рук. Тульчинский & 115 км \\
\hline R04 & рук. Килийский - Измаил, 10 км выше & 103 км \\
\hline R05 & рук. Килийский - Измаил & 96 км \\
\hline R06 & рук. Килийский - Измаил, 1 км ниже & 89,9 км \\
\hline R07 & рук. Килийский - Килия, 4 км выше & 49 км \\
\hline R08 & рук. Килийский - Килия, 6 км ниже & 39 км \\
\hline R09 & рук. Килийский - Килия, 13 км ниже & 32 км \\
\hline R10 & рук. Килийский - Вилково, 1 км выше & 21 км \\
\hline $\mathbf{R} 13 / 1$ & рук. Быстрый & $1.0 \mathrm{Kм}$ \\
\hline
\end{tabular}

Таблица 1. Расположение пунктов мониторинга качества воды в дельте р. Дунай, данные которых использовались для прогнозирования

Результаты исследования. Усредненные по всем пунктам мониторинга исходные данные о показателях качества воды, расчетные значения временных тенденций для каждого показателя и уровни их значимости приведены в табл. 2. 
Таблица 2. Значения показателей качества воды, усредненные по всем пунктам наблюдений в украинской части дельты р. Дунай, и их временные тенденции

\begin{tabular}{|c|c|c|c|c|c|c|}
\hline \multirow[b]{2}{*}{$\begin{array}{c}\text { Год } \\
\text { наблюдения }\end{array}$} & \multicolumn{6}{|c|}{ Показатели качества речной воды } \\
\hline & $\begin{array}{c}\text { БПК-5, } \\
\mathrm{M \Gamma O}_{2} / \text { дм }^{3}\end{array}$ & $\begin{array}{c}\text { Азот } \\
\text { аммонийный, } \\
\text { мг/дм }{ }^{3}\end{array}$ & $\begin{array}{c}\text { Азот } \\
\text { нитритный, } \\
\text { мг/дм }{ }^{3}\end{array}$ & $\begin{array}{c}\text { Фосфор } \\
\text { фосфатов, } \\
\text { мГР/дм }\end{array}$ & $\begin{array}{l}\text { Марганец, } \\
\text { мкг/ дм }\end{array}$ & $\begin{array}{l}\text { Хром+6, } \\
\text { мкг/ дм }\end{array}$ \\
\hline 2004 & 1,61 & 5,27 & 0,06 & 0,23 & - & - \\
\hline 2005 & 2,32 & 0,20 & 0,03 & 0,10 & 8,2 & - \\
\hline 2010 & 1,89 & 0,09 & 0,02 & 0,05 & 8,0 & 7,18 \\
\hline 2011 & 1,54 & 0,07 & 0,02 & 0,04 & 11,0 & 8,33 \\
\hline 2012 & 1,50 & 0,14 & 0,03 & 0,04 & 8,8 & 9,00 \\
\hline 2013 & 1,50 & 0,12 & 0,03 & 0,04 & 40,9 & 6,23 \\
\hline 2014 & 1,16 & 0,09 & 0,03 & 0,05 & 16,7 & 4,64 \\
\hline 2015 & 1,17 & 0,04 & 0,02 & 0,04 & 34,2 & 2,57 \\
\hline 2016 & 1,29 & 0,06 & 0,01 & 0,04 & 43,8 & 3,48 \\
\hline 2017 & 1,81 & 0,08 & 0,02 & 0,04 & 25,6 & 2,77 \\
\hline $\begin{array}{l}\text { Временная } \\
\text { тенденция, } \\
\text { ед.изм./год }\end{array}$ & $-0,047$ & $-0,238$ & $-0,002$ & $-0,010$ & 2,693 & $-0,904$ \\
\hline $\begin{array}{c}\text { Уровень } \\
\text { значимости } \\
\text { тенденции }\end{array}$ & 0,02 & 0,05 & 0,02 & 0,01 & 0,05 & 0,004 \\
\hline
\end{tabular}

Как видно из приведенных в табл. 2 результатов расчетов, по большинству показателей качества речной воды в среднем по пунктам мониторинга украинской части дельты р. Дунай были выявлены тенденции к улучшению качества воды. Наблюдалось уменьшение значений показателей азот аммонийный, азот нитритный, фосфор фосфатов, БПК-5 и хром ${ }^{6+}$. Тенденция к ухудшению качества воды была определена только по показателю марганец. Значительное увеличение концентрации марганца наблюдалось, начиная с 2013 г. Если до 2012 г. концентрации марганца были на уровне рыбохозяйственной ПДК, то начиная с 2013 г. они в несколько раз превышали рыбохозяйственные нормативы. То есть эта тенденция обусловлена ухудшениям качества воды за пределами украинской части дельты.

Поскольку прогнозирование качества воды в данной работе осуществлялось по среднегодовым значениям показателей, для построения прогнозов применялся метод Хольта [9]. Этот метод является модификацией метода экспоненциального сглаживания, которая учитывает временную тенденцию прогнозируемого показателя. Применение данного метода состоит в выполнении расчетов согласно следующей системе из двух рекуррентных формул:

$$
\left\{\begin{array}{l}
C_{t+1}^{p}=\lambda \cdot C_{t}^{p}+(1-\lambda) \cdot\left(C_{t}+T_{t}\right) \\
T_{t+1}=\gamma \cdot T_{t}+(1-\gamma) \cdot\left(C_{t}^{p}-C_{t-1}^{p}\right)
\end{array},\right.
$$

где $C_{t}$ - фактическое значение показателя в момент времени $t$,

$C_{t}^{p}-$ прогнозное значение показателя в момент времени $t$,

$T_{t}$ - сглаженная тенденция показателя в момент времени $t$;

$\lambda$ и $\gamma$ - параметры сглаживания соответственно значений показателя и его тенденции. Параметры сглаживания лежат в пределах интервалов $0 \leq \lambda \leq 1$ и $0 \leq \gamma \leq 1$. Результаты прогнозирования для усредненных по всем пунктам мониторинга значений показателей на период времени до 2020 г. приведены в табл. 3.

Как видно из приведенных в табл. 3 результатов прогнозирования, ухудшение качества воды в ближайшие года ожидается не только по показателю марганец, но также по показателям БПК-5 и азот аммонийный. Для данных показателей в 2017 году наблюдалась положительная сглаженная тенденция. Однако ожидаемое увеличение показателей БПК-5 и азот аммонийный является несущественным; их значения останутся на уровне ниже, чем рыбохозяйственные ПДК. Концентрация марганца согласно прогнозу на 2020 г. достигнет уровня более трех ПДК. Тенденции к ухудшению качества воды по всем указанным показателям наблюдаются уже во входном створе украинской части дельты р. Дунай (выше г. Рени). То есть эти тенденции обусловлены трансграничным загрязнением. 
Таблица 3. Краткосрочный прогноз изменений показателей качества воды в среднем по пунктам мониторинга украинской части дельты р. Дунай

\begin{tabular}{|c|c|c|c|c|c|}
\hline \multirow{2}{*}{$\begin{array}{c}\text { Показатели качества } \\
\text { воды }\end{array}$} & \multirow{2}{*}{$\begin{array}{c}\text { Сглаженная } \\
\text { тенденция, } \\
\text { од.вим.год }\end{array}$} & \multicolumn{4}{|c|}{ Год наблюдений } \\
\hline & & 2017 & 2018 & 2019 & 2020 \\
\hline БПК-5, мгО $2 /$ дм $^{3}$ & 0,03 & 1,81 & 1,74 & 1,77 & 1,80 \\
\hline $\begin{array}{l}\text { Азот аммонийный, } \\
\text { мгN/дм }{ }^{3}\end{array}$ & 0,008 & 0,08 & 0,08 & 0,09 & 0,10 \\
\hline $\begin{array}{l}\text { Азот нитритный, } \\
\text { мгN/дм }\end{array}$ & $-0,001$ & 0,02 & 0,017 & 0,016 & 0,015 \\
\hline $\begin{array}{c}\text { Фосфор фосфатов, } \\
\text { мГР/дм }\end{array}$ & $-0,01$ & 0,04 & 0,035 & 0,027 & 0,019 \\
\hline Марганец, мкг/дм ${ }^{3}$ & 0,82 & 27,6 & 28,4 & 29,3 & 30,1 \\
\hline Хром+6, мкг/дм & $-0,49$ & 2,8 & 2,4 & 1,9 & 1,4 \\
\hline
\end{tabular}

Выводы. 1. С помощью разработанной геоинформационной системы экологического мониторинга украинской части дельты р. Дунай определены значимые тенденции изменения за период 2005-2017 гг. следующих показателей качества речной воды: БПК-5, азот аммонийный, азот нитритный, фосфор фосфатов, хром ${ }^{6+}$ и марганец.

2. В среднем за указанный период наблюдений по показателю марганец наблюдалась тенденция к ухудшению качества воды, а по остальным показателям - тенденция к улучшению качества воды.

3. Значение всех показателей качества воды, кроме марганца, не превышали рыбохозяйственных нормативов. Концентрация марганца до 2013 г. была на уровне рыбохозяйственной ПДК, но начиная с 2013 г. наблюдалось существенное превышение рыбохозяйственных нормативов.

4. Превышение нормативов по показателю марганец и тенденция к его увеличению наблюдались уже во входном створе украинской части дельты р. Дунай (выше г. Рени), то есть эта тенденция обусловлена ухудшением качества воды за пределами украинской части дельты.

5. Краткосрочное прогнозирование изменений качества воды за методом Хольта показывает, что следует ожидать ухудшение качества воды по показателям азот аммонийный, БПК-5 и марганец. Увеличение показателей азот аммонийный и БПК-5 ожидается несущественным: эти показатели останутся на уровне ниже рыбохозяйственных ПДК. Концентрация марганца будет превышать ПДК приблизительно в 3 раза. По сдаче показателей следует ожидать улучшение качества воды.

6. Тенденции к ухудшению качества воды по показателям азот аммонийный, БПК-5 и марганец в последние годы обусловлены трансграничным загрязнением.

\section{ЛИТЕРАТУРА}

1. Water Quality in the Danube River Basin - 2006 / Ed. I. Liška. - ICPDR - International Commission for the Protection of the Danube River. - TNMN - Yearbook: Vienna, 2006 - 39 p.

2. Danube River Basin Geographic Information System [Электронный pecypc] URL: https://www.danubegis.org/.

3. Геоінформаційна система якості поверхневих вод Держводагентства України [Электронный ресурс] URL: http://watermon.iisd.com.ua/

4. Мокін В.Б. Геоінформаційна аналітична система моніторингу якості і використання водних ресурсів та стану водогосподарських об’єктів річки Тиса у Закарпатській області/ Мокін В. Б., Мокін В.І., Чіпак В.П. та інші - Вінниця: УНІВЕРСУМ-Вінниця, 2009.- 226 с.

5. Мокін В.Б. Система підтримки прийняття управлінських рішень керівниками водогосподарських організацій для басейну річки Дністер з використанням геоінформаційних технологій/ Мокін В. Б., Мокін В.І., Бабіч М.Я. та інше - Вінниця: УНІВЕРСУМ-Вінніця, 2009.- 252 с.

6. Мокін В.Б. Система підтримки прийняття управлінських рішень керівниками водогосподарських організацій для басейну річки Сіверський Донець 3 використанням геоінформаційних технологій/ Мокін В. Б., Мокін В.І., Бабіч М.Я. та інші - Вінниця: УНІВЕРСУМ - Вінніця, 2009.- 352 с.

7. Деякі результати комплексного екологічного моніторингу довкілля української частини дельти р. Дунаю / О. Г. Васенко та ін. Проблеми охорони навколишнього природного середовища та екологічної безпеки. Зб. наук. праць УКРНДІЕП. Харків: Райдер, 2014. Вип. XXXVI. - С. 176-190.

8. Результати комплексного екологічного моніторингу довкілля під час експлуатації глибоководного судового ходу р. Дунай-Чорне море у 2017 році / О. Г. Васенко та ін. Екологічна безпека: проблеми і шляхи вирішення. Зб. наук. ст. XIV Міжнародної науково-практичної конференції (м. Харків, 10-14 вересня 2018 р). Харків: Райдер, 2018. - С. 87-91.

9. Шикин Е.В., Чхартишвили А.Г. Математические методы и модели в управлении. - М.: Дело, 2000. - 431 с. 